DOI: https://doi.org/10.33739/2587-5434-2020-3-119-125

\title{
FILM TRAILER IN TEACHING ENGLISH TO NON-ENGLISH MAJOR STUDENT
}

\author{
Leila Diasamidze \\ Doctor of Philology, Assistant professor \\ Batumi Shota Rustaveli State University \\ (Batumi, Georgia) \\ e-mail: leila.diasamidze82@mail.ru
}

\begin{abstract}
The active use of innovative technologies in teaching increases its effectiveness and contributes to the development of skills and abilities in the process of teaching foreign languages. Internet resources as a supplementary teaching tool include short trailers. Learning English with original language trailers is an effective way to English speaking skills. Short movie trailers can help you learn to comprehend speech, understand words in context and think in English, stimulating creativity in the educational process. Thanks to visual video materials, speech situations are created that are close to real ones. The use of film trailers contributes to the expansion of cultural knowledge and the general outlook of students. Tasks for the video series of trailers not only form socio-cultural competencies and communication and listening skills, but also increase the motivation of students in learning English. The article points out the moments that contribute to learning English from trailers with scenes from films.
\end{abstract}

Keywords: trailer, video didactics, listening, subtitles, visual content

\section{ПРИМЕНЕНИЕ ВИДЕОДИДАКТИКИ ТРЕЙЛЕРОВ В ПРЕПОДАВАНИИ АНГЛИЙСКОГО ЯЗЫКА}

\author{
Лейла Диасамидзе \\ PhD, ассистент профессора \\ Батумский государственный университет \\ имени Шота Руставели \\ (Батуми, Грузия) \\ e-mail: leila.diasamidze82@gmail.ru
}

\begin{abstract}
Аннотация. Активное использование инновационных технологий в арсенале средств обучения повышает его эффективность и способствует развитию навыков и умений в процессе обучения иностранным языкам. Ресурсы Интернета, как вспомогательного инструмента обучения, включают короткометражные трейлеры. Изучение английского языка с помощью трейлеров на языке оригинала, - эффективный способ усвоить языковые навыки. Короткие фильмы-трейлеры, помогая учиться воспринимать речь на слух, понимать слова в контексте и думать на английском языке, стимулируют творческий подход к учебному процессу. Благодаря наглядным видеоматериалам создаются речевые ситуации, приближенные к реальным. Использование обучающих трейлеров способствует расширению культурологических знаний и общего кругозора студентов. Задания к
\end{abstract}


видеоряду трейлеров не только формируют социокультурные компетенции и навыки коммуникации и аудирования, но и повышают мотивацию студентов при изучении английского языка. В статье указаны моменты, способствующие изучению английского языка по трейлерам со сценами из фильмов. В частности, при использовании трейлеров художественных фильмов в преподавании необходимо учитывать соответствие языкового содержания фильма уровню знаний и психологическим особенностям студентов.

Ключевые слова: трейлер, видеодидактика, аудирование, субтитры, визуальный контент.

\section{ВВЕДЕНИЕ. ОБЗОР ЛИТЕРАТУРЫ И ВИДЕОРЕСУРСОВ}

Преподавание английского языка на основе трейлеров аутентичных художественных фильмов имеет большой дидактический потенциал. Фактически трейлер является рекламой фильма, состоящей из его отрывков. В кинематографе трейлером (англ. trailer, от trail «след») по определению называют небольшой видеоролик, используемый для анонсирования или рекламы фильма (https://ru.wikipedia.org/wiki). Связный сюжет позволяет даже называть трейлер минифильмом(Глазова,Савельева:https://cyberleninka.ru/viewer_images/17810737/f/1.png). Согласно определению Американской академии киноискусства, короткометражный фильм - "short films" или "shorts“ длится не более 40 минут, включая полные титры. Исходя только из экранного времени, к категории короткометражных фильмов относят самые разные типы видеоматериалов: реклама, трейлеры, музыкальные клипы, мультфильмы, а также собственно короткие фильмы, художественные и документальные. Этот формат позволяет при небольшом бюджете снять настоящее кино с диалогами, музыкой интересным визуальным рядом. Подобные короткометражные ленты помогают упражняться в английском языке при небольших временных затратах. Изучение английского языка с помощью фильмов на языке оригинала, - самый эффективный способ освоить и отшлифовать языковые навыки. Кроме того, трейлеры помогают ориентироваться в новинках кинематографа. Короткие фильмы-трейлеры, помогают учиться восприятию речи на слух, понимать слова в контексте и думать на английском языке; они стимулируют творческий подход к учебному процессу. Благодаря наглядным видеоматериалам, создаются речевые ситуации, приближенные к реальным. При использовании трейлеров художественных фильмов в дидактике необходимо учитывать соответствие языкового содержания фильма уровню знаний и психологическим особенностям студентов. Использование обучающих трейлеров также способствует расширению культурологических знаний и общего кругозора студентов. Задания к видеоряду трейлеров не только формируют социокультурные компетенции и навыки коммуникации и аудирования, но и способны максимально повышать мотивацию студентов при изучении английского языка.

Существует множество каналов, предоставляющих возможности для лучших приемов обучения и совершенствования знаний английского языка с помощью трейлеров. Коротко ознакомим с некоторыми из них. Так, канал Movieclips trailers оперативно выкладывает самые свежие трейлеры фильмов и короткие видео с различных кинофестивалей. При желании в каждом ролике можно включить субтитры на английском. Команда Screen Rant сотрудничает со студиями Disney, Warner Brothers, Marvel, Universal Pictures, чьи уникальные видео содержат интересные детали и секреты известных кинолент.

Девиз команды канала CinemaSins, насчитывающего более 5 миллионов подписчиков - «Не бывает фильмов без смешных оплошностей», вполне оправдан; преподаватель сможет обыграть на занятиях самые нелепые несоответствия известных кинолент. Все ролики имеют субтитры на английском. Канал Clevvermovies содержит подборки лучших фильмов разных жанров, в том числе комиксов. WatchMojo, седьмой по величине канал YouTube, имеет более 10 миллионов подписчиков и сотни 
видео. Авторы выкладывают видео подборки лучших фильмов разных жанров. На канале Filmisnowextra его авторы выкладывают удаленные из кинолент сцены и серии интервью, где создатели картин рассказывают подробности о съемках и своих планах. Авторы канала SciFiHorrorTrailers выкладывают самые свежие трейлеры к фильмам жанров «хоррор» и «научная фантастика».

Авторы канала Mr Sunday Movies выкладывают обзоры трейлеров, а также интересные сцены из кинолент. Рекомендуем обратить особенное внимание на так называемые "Easter eggs" («пасхальные яйца»). Так называют разнообразные скрытые сюрпризы и загадки от создателей фильма. В его плейлисте раздел, посвященный комиксам, создает прекрасную возможность для развития навыков аудирования. C помощью трейлеров канала Science vs Cinema студенты узнают много интересных научных фактов на основе трейлеров популярных кинолент. В интернете много сайтов, где выложены отдельные сцены из фильмов на английском языке. Но есть ресурс, который помогает без труда найти видео на любую нужную вам тему. Лучшие трейлеры, а также другие видео для изучения английского языка, можно найти на сайте или в мобильном приложении FluentU. Видео на сайте FluentU можно отсортировать по степени языковой сложности (от уровня beginner до native), по теме (искусство и развлечения, медицина и здоровье, и т.п.) и жанру (видеоблоги, выпуски новостей, телепередачи и пр.).

Поскольку у всех видео на сайте есть интерактивные субтитры, можно узнать значение любого слова в контексте во время просмотра, а также увидеть к нему иллюстрацию и прослушать его произношение. К любому слову сайт подбирает дополнительные примеры, демонстрирующие его употребления. Обучающий языковой сайт Mango Premiere использует особый метод, помогающий понимать письменный текст и устную английскую речь с помощью субтитров. На сайте есть два режима: "Movie Mode" и "Engage Mode“. В режиме "Movie Mode" трейлер воспроизводится с субтитрами, позволяя сопоставить звуковой ряд с письменным текстом. Очень ценно то, что на сайте имеется раздел «Культура», помогающий понять непереводимую игру слов и необычные шутки, включающие фразеологизмы.

На сайте YouTube есть тысячи отрывков и сцен из разных фильмов, способствующих изучению новой лексики и отработке навыков разговорной речи. Упомянем большую коллекцию занятий по английскому языку на основе сцен из фильмов, где каждая сцена показывается студентам несколько раз, а затем с субтитрами и объяснением ключевых слов. Следующий сайт Британского Совета British Council Film также использует сцены из фильмов и трейлеры для обучения английскому языку. Студенты смотрят короткие видео, а затем выполняют упражнения на их основе, одновременно вырабатывая навыки аудирования. Перед первым просмотром выполняются подготовительные упражнения, а затем обучающиеся смотрят ролик. В итоге просмотр завершается тренировочными упражнениями.

\section{НОВИЗНА МЕТОДИКИ ПРИМЕНЕНИЯ ВИДЕОДИДАКТИКИ}

Специальной литературы по вопросу применения трейлеров, как одного из видов лингводидактики, еще не наработано ввиду новизны этого вида лингводидактики. Существуют в основном отдельные рекомендации практиков и авторов определенных каналов. Отдельные найденные разработки посвящены узкоспециальному применению, - например, преподаванию английского языка в области медицины. Тем не менее, всячески подчеркивается эффективность применения этого относительно нового средства лингводидактики. Так, Тереза Мупас, преподаватель английского языка как иностранного, настоятельно рекомендует учить английский язык по короткометражным фильмам (Mupas: https://englex.ru/youtube-channels-about-films/). Другой профессиональный преподаватель 
английского языка, Киран Донахи, ведущий сайт Film-English.com, также призывает всех использовать эти короткометражные фильмы во время аудиторных занятий, так как это вносит в обучение элемент творчества и заставляет несколько отвлечься от таких теоретических материй, как грамматика (Film English - by Kieran Donaghy: https://film-english.com/).

В работе преподавателя необходимо учитывать ряд моментов, способствующих изучению английского языка по трейлерам со сценами из фильмов. Для того, чтобы выбранный трейлер «работал» на занятии, он должен соответствовать некоторым критериям. Прежде всего, необходимо выбрать трейлер, подходящий по содержанию и уровню трудности конкретной студенческой группе. При выборе ресурса, обращайте внимание на градацию уровней: elementary, pre-intermediate, intermediate. Такое деление облегчает поиск. Ведь самый лучший видеоматериал не производит впечатления, если он слишком сложен. При этом важно учитывать заинтересованность студентов конкретным материалом, а также его соответствие теме урока и его цели. Обычно видео используют для практики аудирования, с целью пополнения словарного запаса и тренировки некоторых грамматических форм или же для расширения содержательного поля дискуссии. Хорошее качество записи и четкость произношения особенно актуальны для начинающих, имеющих проблемы с аудированием.

В зависимости от типа восприятия, Тереза Мупас, в частности, советует при ведущем визуальном восприятии периодически ставить фильм на паузу, пытаясь перечислить вслух содержание кадра. Если в первую очередь воспринимается звуковая информация, то следует мысленно соотнести звуковой ряд картины с ситуацией, стараясь запомнить выражение или часть диалога. При этом при просмотре фильма дается задание обдумать и подготовить вопросы по его содержанию. Поскольку все трейлеры коротки по форме, их удобно посмотреть дважды, чтобы найти правильный ответ. Например, автор предлагает рассмотреть трейлер к фильму "Blind Vaysha” / «Слепая Вайша»; в 2017 году фильм был номинирован на премию «Оскар». Сюжет повествует о девушке, видящей одним глазом только будущее, а другим - только прошлое. Это анимированная лента, в которой режиссер использовала собственные картины. Вы увидите то, что видит Вайша своими разными глазами, и как на нее реагируют жители деревни.

Автор предлагает следующую типовую структру для работы над трейлером: 1. Активный словарь: adoration, sighted person, blind, affliction, to convince, a gaggle of women, to reunite, to restore, vision, to topple, to lay eyes on, nightmares, to split, abyss, void, ruins, apocalypse, disability, reassuring, preceding. 2. Вопросы для обсуждения: A. What is the message of the movie? Do you agree or disagree with the message? В чем основная мысль ленты? Вы согласны с ней или нет?) В. How did the color of the images and the music affect how you felt while you watched the movie? (Какое действие на вас оказывают цвет картин и музыка?) (Mupas:idem).

Особое внимание необходимо уделить предосмотру, задача которого состоит в обогащении творческого потенциала студентов и установлении связи между предъявленными словами и содержанием видео. Цель предосмотра - понимание содержания и дальнейшее активное рефлексивное и критическое наблюдение; с этой целью осуществляется предварительный просмотр и описание содержания фильма с поставленными в нем проблемами.

Отметим также важность понимания сюжета, чтобы лучше воспринимать его детали и уделять больше внимания языковой стороне диалогов. Если уровень студентов - beginner, то поначалу следует просмотреть сцены трейлера с субтитрами. Можно порекомендовать следующие виды работы с субтитрами, представляющими прекрасный способ пассивного усвоения языка. Включая в трейлер английские субтитры, с каждым просмотром увеличивается запоминание новой лексики и словосочетаний. Метод «интервального повторения» зарекомендовал себя как очень эффективный: 
спустя некоторое время следует вернуться к отрывку, повторяя и закрепляя в памяти новые слова и выражения. Например, эпизод из трейлера фильма “Groundhog Day” («День сурка») - прекрасный образец того, как может происходить знакомство. Диалог прост, но в нем содержится много вопросов, которые можно задать для поддержания беседы. Поскольку в трейлере много раз повторяются одни и те же сцены и разговоры, студенты многократно смотрят одну и ту же сцену до тех пор, пока не выучат без труда её реплики и не смогут самостоятельно озвучить повторяющиеся эпизоды.

Возможно использование и двойных субтитров, хотя английские субтитры предпочтительнее. На начальном этапе обучения желательно использовать двойные субтитры на английском и на родном языке. Следует учесть, что хотя двойные субтитры помогают лучше понять содержание, все же довольно сложно читать субтитры на двух языках и следить одновременно за происходящим на экране. Вероятно, лучшим будет сосредоточиться на английских субтитрах, а к переводу на родной язык обратиться только в случаях затруднений. Есть несколько способов использования трейлеров на английском языке без субтитров, «обыгрывая» в группе особенно интересные идиомы, выражения и лингвокультурологические особенности. Студенты могут произносить реплики до их произнесения персонажем и даже, приглушив звук, говорить вместе с ним, копируя его произношение. Записав себя на диктофон, затем они могут сравнить свое произношение и темп речи с оригиналом. Материал запомнится еще лучше, если провести игру или ответить на проверочные вопросы по хорошо усвоенному эпизоду. После того, как группа посмотрела несколько эпизодов из трейлеров, каждый выбирает понравившуюся реплику или сцену, чтобы записать ее на листочке. Сложив листочки и перемешав их, студенты тянут по очереди, чтобы определить персонаж, которому принадлежит реплика или трейлер, в котором она прозвучала.

Приведем другие примеры из практики, демонстрирующие возможности использования трейлеров. Так, перед демонстрацией трейлера к фильму «Dangerous Lies» («Опасная ложь»), в качестве предфильмовых ориентиров можно предложить заранее заготовленные на слайдах портреты персонажей (Katie, Adam, Leonard, Julia, Mrs Chestler) и ключевые слова (https://www.youtube.com/watch?v=EzJJo0whbJ4). Студенты должны связать их с персонажами, например, money, attorney, caretaker, investigation, diamonds, debt, etc. и высказать свои предположения о сюжете фильма и возможной профессии героев и т.п. Возможен также просмотр трейлера в беззвучном режиме, по которому студенты должны сделать свои предположения о возможном сюжете фильма. Целью этих заданий на этапе предосмотра является повышение креативности студентов при помощи установления логических связей между ключевыми словами, персонажами и видео контентом.

Необходимым условием второго, демонстрационного этапа, является контроль понимания. Он может состоять из верных и неверных утверждений (е.g.: Katie and Adam are a young married couple struggling to pay their bills. T/F), а также вопросов открытого типа (e.g.: Why is the caretaker was so upset?). Коммуникативные задания для проработки лексики и соответствующих грамматических моментов также имеют большое значение для достижения поставленных коммуникативных задач. Целью заданий является проверка студентов на понимание и выявление проблемных для них моментов. Таковыми могут стать для аудитории некоторые лексические единицы, например, «bе broke» («быть на мели», «обанкротиться») или же выражение «make it this far» («зайти далеко», «преодолеть препятствия») с целью уделить внимание их дальнейшей проработке. Для этого могут быть использованы такие типы упражнений, как «matching» и «gap-filling», например:

- $\quad$ matching the words and their definitions:

1) caretaker ---- a) a person employed to look after people or animals

2) couple of weeks - b) more than two weeks or about less 
3) be broke -------- c) moneyless, having completely run out of money

- gap-filling:

I am always...... by the end of the month (answer: broke)

Поскольку визуализация является ключевым моментом, также можно использовать ассоциативные связи картинок, соответствующих набору фраз, взятых из диалогов трейлера к фильму.

(ответ к картинке слева: «to treat oneself», справа: «be broke»
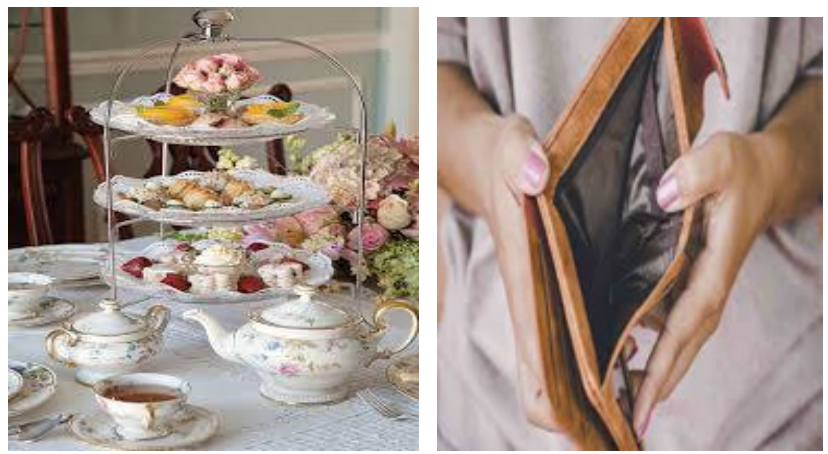

После демонстрации видеофрагмента на следующем этапе планируется проведение дискуссии, прогнозирование сюжета фильма, описание проблем и ролевое исполнение ключевых моментов. Целью данных задач является закрепление понимания и развитие навыков критического мышления.

\section{ЗАКЛЮЧЕНИЕ}

Итак, преимущества трейлеров к фильмам очевидны в качестве одного из ресурсов видео дидактики для развития и совершенствования языковых навыков учащихся. Этот ресурс улучшает понимание разговорного английского, создает мотивацию студентов, знакомя их с культурной и межкультурной спецификой. С помощью видео контента трейлеров студенты приобретают навыки функционального использования английского языка в определенном контексте, а также изучения новых лексических единиц и грамматических структур, параллельно улучшая свое произношение. Выделим моменты, способствующие изучению английского языка по трейлерам: 1. соответствие уровня их сложности конкретной студенческой группе; 2. заинтересованность содержанием трейлера; 3. разнообразие методов и подходов изучения языка с помощью видеоресурсов (интервальное повторение, активное использование двойных субтитров, имитация и отработка произношения, различные игровые ситуации и т.п.). Особое внимание уделяется предосмотру, задача которого состоит в обогащении творческого потенциала учащихся и установлении связи между предъявленной лексикой и содержанием трейлера.

\section{LIST OF REFERENCES}

Biletsky Volodymyr, Onkovych Anna \& Yanyshyn Olha (2019) MEDIA EDUCATION TECHNOLOGIES IN DEVELOPING STUDENTS' PROFESSIONAL COMPETENCE // International ScientificPedagogical Organization of Philologists "WEST-EAST "(ISPOP). Scientific Journal "WEST-EAST" Vol. 2\2, N1 (October, 2019), p.p. 110-114. https://doi.org/10.33739/2587-5434-2019-2-2-110-114

Donaghy, K. Film English - by Kieran Donaghy.// https://film-english.com/

Dudushkina, Svetlana V. (2019) THE VIDEO COURSE OF FOREIGN LANGUAGE: FOCUS ON STUDENT'S AUTONOMOUS ACTIVITY // International Scientific-Pedagogical Organization of Philologists "WEST-EAST" (ISPOP). Scientific Journal "WEST-EAST". Vol. 2\2, N1 (October, 2019). pp. 125-129. https://doi.org/10.33739/2587-5434-2019-2-2-125-129 
Glazova, M.S., Savel'yeva, O.O. Treyler: ekrannaya reklama ili minifil'm? [Trailer: screen advertising or minifilm?] //https://cyberleninka.ru/viewer_images/17810737/f/1.png

Goyo, G., Churmanteeva, K. Kak uchit' angliyskiy po stsenam iz fil'mov. [How to learn English from movie scenes]// www.fluentu.com > blog

Meyer T.P., Krivosheyeva Ye. N. K voprosu ob ispol'zovanii fil'mov v obuchenii angliyskomu yazyku studentov meditsinskikh spetsial'nostey.//[On the use of films in teaching English to students of medical specialties]/https://cyberleninka.ru/article/n/k-voprosu-ob-ispolzovanii-filmov-v-obucheniiangliyskomu-yazyku-studentov-meditsinskih-spetsialnostey

Mupas, T. 11 awesome video channels in English about movies, filming and movie bloopers. https://englex.ru/youtube-channels-about-films/ Published: 26.02.2016.

Trailer://https://ru.wikipedia.org/wiki/

Onkovych, H. \& Onkovych, A. (2020). Media Didactics as a way to comprehend professionally-oriented terminological systems $\backslash$ International Scientific-Pedagogical Organization of Philologists "WESTEAST"(ISPOP). Scientific Journal WEST-EAST Vol. 3, N1 (March, 2020). pp. 38-46. doi: https://doi.org/10.33739/2587-5434-2020-3-1-38-46

\section{For citation:}

Diasamidze, L. (2020) Film trailers in teaching English to non-english major students // International Scientific-Pedagogical Organization of Philologists "WEST-EAST" (ISPOP). Scientific Journal "WESTEAST”. Vol. 3, N1 (October, 2020). pp. 119-125. https://doi.org/10.33739/2587-5434-2020-3-119-125

\section{Для цитирования:}

Диасамидзе, Л. Я. (2020) Применение видеодидактики трейлеров преподавании английского языка // International Scientific-Pedagogical Organization of Philologists "WEST-EAST" (ISPOP). Scientific Journal "WEST-EAST". Vol.3, N1 (October, 2020). C. 119-125. https://doi.org/10.33739/2587-5434-2020-3-119125

\section{Information about the author:}

Diasamidze Leila - PhD in Philology, Assistant professor, Batumi Shota Rustaveli State University, Batumi, Georgia.

e-mail: leila.diasamidze@ bsu.edu.ge

\section{Сведения об авторе:}

Диасамидзе Лейла Яковлевна - доктор филологии, ассистент профессора, Батумский государственный университет имени Шота Руставели, Батуми, Грузия.

e-mail: leila.diasamidze@bsu.edu.ge 